\title{
Load-Carrying Capacity Analysis on Derrick of Offshore Module Drilling Rig
}

\author{
Feng Guan ${ }^{1}$, Chuanxi Zhou ${ }^{1, *}$, Shizhong Wei ${ }^{1,2}$, Wenxiu Wu ${ }^{1}$ and Xianzhong $\mathrm{Yi}^{1}$ \\ ${ }^{1}$ School of Mechanical Engineering, Yangtze University, Jingzhou 434023, China; ${ }^{2}$ School of Materials Science and \\ Engineering, Henan University of Science and Technology, Luoyang 471023, China
}

\begin{abstract}
Offshore module drilling rig has become an important equipment of offshore oil and gas development, especially, the significantly future application in the field of deep water. Due to the long time working and complex working conditions of in-service derrick of offshore module drilling rig, analysis of its load-carrying capacity assessment is of great significance. Field test shows that in common the derrick of offshore module drilling has an intrinsic defect of stress concentration in addition to external damages including initial bending and load eccentricity. In this paper, the finite element method is combined with field test method, two assessment methods are put forward, respectively. Stress concentration detection on derrick main rod is carried out by using metal magnetic memory detector, and the detection results show that larger degree of stress concentration phenomenon exists on eleven rods of derrick, and stress concentration degree of individual rod is serious. Loading stress test and finite element analysis are carried out on the derrick of offshore module drilling rig. According to comprehensive comparison, it is concluded that hoisting capacity for the derrick cannot reach $4500 \mathrm{kN}$. Two kinds of structure reinforcement scheme are proposed, and comparison results show that the reinforcement scheme with four legs can improve the actual load-carrying capacity of the derrick. Reinforced derrick can achieve the new design value of derrick carrying capacity. In this study, the evaluation method is correct, which can analyze the derrick carrying capacity of offshore module drilling rig more objective and accurate, and we also provide a new train of thought and reference for the steel structure carrying capacity assessment.
\end{abstract}

Keywords: Assessment method, derrick, finite element analysis, load-carrying capacity, offshore drilling rig, stress concentration detection.

\section{INTRODUCTION}

With the exploration and development of offshore oil and gas going into the deep water, application of offshore module drilling rig (OMDR) with large load-carrying capacity is used increasing widely. For example, dual derrick drilling unit has been applied well in ocean drilling operation [1-3]. Recently, a majority of drillings and workovers used in china offshore platform have entered late period of service, and many of them have also been modified, destroying the original structure and carrying characteristics. Many derricks of module drilling rig are carried out capacity assessment after being used 5-6 years or even more than 10 years and can be used for new drilling, which not only lack of accumulation of testing data, but also increase the risk of initial defects that the derrick exists. The assessment results of derrick carrying capacity of OMDR directly determine whether the derrick continues to be used, be repaired or be replaced. Because of the expensive cost to replace derrick on offshore platform, the higher costs for transport and installation than the rig itself, scientific and objective assessment methods, considering various factors, assessing capacity of derrick accurately, should guarantee production safe and efficient, and are of great significance in various aspects.

*Address correspondence to this author at the School of Mechanical Engineering, Yangtze University, Jingzhou 434023, China;

Tel: 0086-716-8062600; Fax: 0086-716-8062081;

E-mails: zcx123@yangtzeu.edu.cn or zcx123tt@163.com
At present, derrick assessment method is established according to the limited test data on derrick and the theory of strength, stiffness, reliability and stability. The above assessment of derrick through linear extrapolation of the limited test data is not comprehensive and scientific. Current studies mostly focus on theoretical method and model with no damage defect [4-6]. Guo and Fukumoto [4] proposed the theory which concerned with the post buckling behavior and ultimate load-carrying capacity of thin-walled cold-formed and welded stub columns subjected to a constant load eccentricity or a constant compression eccentricity. Rodsan and Chiorean [5] presented an efficient computer method for inelastic and large deflection analysis of flexibly jointed steel frames. Han and Liu [6] calculated the ultimate carrying capacity by using three-dimensional degenerated curved shell elements. In recent years, the carrying capacity assessment method of derrick with initial defects and the modified model research have some progress [7-8]. Han et al. [7] proposed a novel method based on the partial model updating theory, where the test stresses of the main load-carrying member rods are taken as the key indicators and the relevant design parameters as the input updating objects. Liu et al. [8] deduced the damage functions which reflected three modes of structure damage. The modified model with considering external damage is put forward by this research, but it has not been verified very well on the spot, and just considering three kinds of common external damage including corrosion, rod bending and eccentric load. Through field test, it is found 
that derrick is of intrinsic defects of stress concentration generally in addition to external damage. The intrinsic defect of stress concentration is just taken into account in derrick carrying capacity assessment model of this study. Through finite element analysis (FEA), combining with loading stress test data, the model is modified, and the modified model can carried out derrick carrying capacity assessment analysis more objectively and accurately. In addition, we will provide a new method and reference for the steel structure carrying capacity assessment.

\section{FIELD TEST}

The scene of test result is the important basis for assessment of derrick and establishment of a finite element model. So we conduct geometric parameters measurement, detection test analysis for the stress concentration, and loading stress test analysis for the module drilling rig derrick, respectively.

\subsection{Geometric Parameter Measurement}

In order to establish an accurate geometric model for FEA and to evaluate the corrosion of derrick of OMDR, the section forms of all rods of derrick are recorded in details, the lengthen of rods are also measured, and measurement of thickness on main rods of derrick is also carried out by ultrasonic thickness measuring unit.

\subsection{Stress Concentration Detection}

Stress concentration is the root of crack and fracture accident for ferromagnetic component. It causes components to abruptly break under the load far less than the yield load, which leads to safety accidents. In recent years, many scholars categorize stress concentration as hidden defects mainly due to the harm of stress concentration and the sudden damage. The metal magnetic memory effect shows that magnetic metals will happen magnetic domain orientation and irreversible orientation again in the stress concentrated area, and the local magnetic anomaly in the magnetic environment will occur, the so-called "leakage magnetic field" is established. The irreversible change of magnetic state will remain after the work load is eliminated. The leakage state on the surface of metal can memorize the micro defects and position of stress concentration. The theory and practice studies have demonstrated that the tangential component $\left(H_{p}(x)\right)$ of magnetic leakage field intensity has a maximum value in the stress concentration area, the normal component $\left(H_{p}(y)\right)$ changes the symbols and zero value will occur. The stress concentration degree can be judged according to the change of $H_{p}(x)$ values [9]. Based on the above principles, we scan and detect the stress concentration of the key roads of derrick by intelligent magnetic memory metal diagnosis instrument. The results show that there are 31 rods which have stress concentration with different degrees, and 11 of the rods have some degree of stress concentration. Fig. (1) shows locations of the 11 rods. Fig. (2) shows the degree of stress concentration for No. 173 rod with increasing length. Table 1 reveals the degree of stress concentration for the rods of derrick with certain stress concentration, in which $H_{p}(x)$, with its unit of $A \cdot m^{-1}$, is the value of the tangential component of magnetic leakage field intensity, and represents the stress concentration degree.

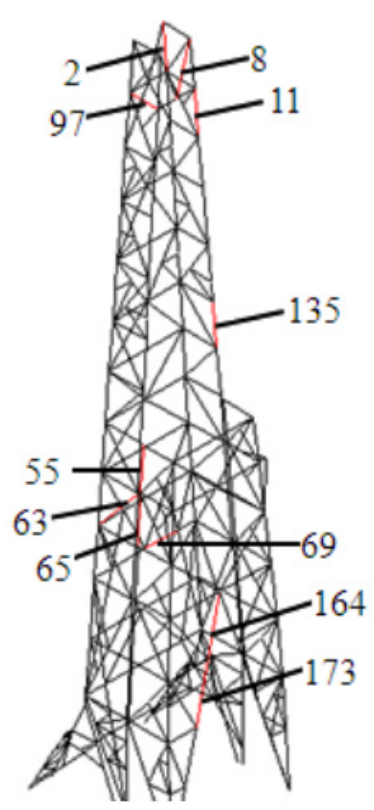

Fig. (1). Locations of 11 rods which have some degree of stress concentration.

According to Table 1, some individual rods have serious stress concentration. For example, the first and the second sections of upper derrick obviously have serious stress concentration for the complexity of the loading on them. Therefore, the stress concentration should be considered by adopting FEA.

\subsection{Loading Stress Test}

According to the provisions of the arrangement of test points in the Specification for Grading and Evaluating the Loading Capacity on Derricks and Substructure of the Drilling Rig and Working Rig [10], the cross-section A-A and cross-section B-B are selected for test point arrangement, together with 32 test points. The height of test points is basically identical in two layers, and position of the test point is shown in Fig. (3). Test gauges' direction is consistent with the axis direction of the derrick leg, and the compensator is perpendicular to the test gauges. Cross section of four legs of the derrick is $\mathrm{H}$, position of strain gauges has also been shown in Fig. (3).

In order to improve the testing sensitivity and to eliminate the influence of the temperature change, stress test adopts half bridge method. Test load should be $25 \%$ greater than that of the design load in standard, the required design load of derrick here is $4500 \mathrm{kN}$, instrument initialization is zero before test, and 3 minutes stop is required for each operating condition. The actual test points are: $270.3 \mathrm{kN}$, $579.2 \mathrm{kN}, 872.6 \mathrm{kN}, 1158.2 \mathrm{kN}$ and $1462.3 \mathrm{kN}$. Fig. (4) shows strain curves of loading process for the test point No. 9.

Table 2 shows the actual measured strain values under the load of $1462.3 \mathrm{kN}$.

Within the elastic range, the derrick stress value is calculated by linear extrapolation method under the original design with maximum hook load of $6500 \mathrm{kN}$, and the results are shown in Table $\mathbf{3}$. 


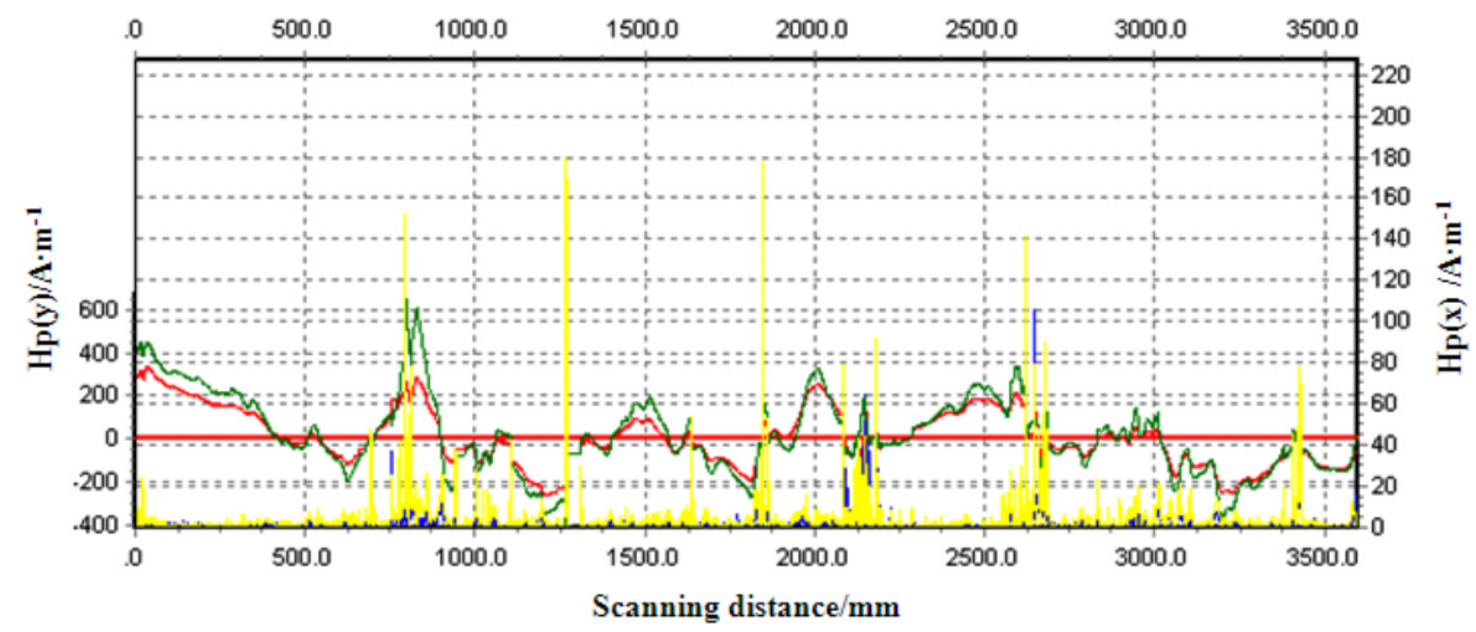

Fig. (2). Stress concentration scan of rod No. 173.

Table 1. Degree of stress concentration for some rods of derrick of OMDR.

\begin{tabular}{|c|c|c|}
\hline No. of Scan Pattern & No. of Passing Zero & $H_{p}(x)\left(A \cdot \mathrm{m}^{-1}\right)$ \\
\hline \hline 2 & 1 & 20 \\
\hline 8 & 14 & 175 \\
\hline 11 & 1 & 15 \\
\hline 55 & 7 & 48 \\
\hline 63 & 2 & 43 \\
\hline 65 & 1 & 8 \\
\hline 69 & 15 & 140 \\
\hline 97 & 5 & 47 \\
\hline 135 & 13 & 140 \\
\hline 164 & 1 & 9 \\
\hline 173 & 20 & 180 \\
\hline
\end{tabular}

\section{FINITE ELEMENT ANALYSIS}

\subsection{Finite Element Model}

First of all, to establish the model of FEA which does not consider the stress concentration of derrick, three dimensional elastic beam elements are chosen. The section types used for derrick modeling are rectangle section, square section, $\mathrm{H}$ section and $\mathrm{L}$ section. 93 types of cross-section are defined and 93 groups of cross-section geometry data can be corresponding derived at the same time. The derrick material performance is close to ASTM A572 Grade steel 50 according to the preliminary field test analysis, the Modulus of elasticity is $2.06 \times 10^{11} \mathrm{~Pa}$, Poisson's ratio is 0.27 , and the density is $7850 \mathrm{~kg} / \mathrm{m}^{2}$. According to the element type, the section types, geometry data of cross-section and the description of the material properties, the model of FEA for derrick is established. The determination of nodes in model should follow the following principles: (1) The nodes of the derrick where rod-rod welding points connect are the model nodes; (2) The junction of derrick and platform are the nodes of the model. Comprehensive consideration, the size of FEA element is $0.1 \mathrm{~m}$, by meshing, and there are 15590 nodes and 11736 elements for this model of FEA, which are shown in Fig. (3).

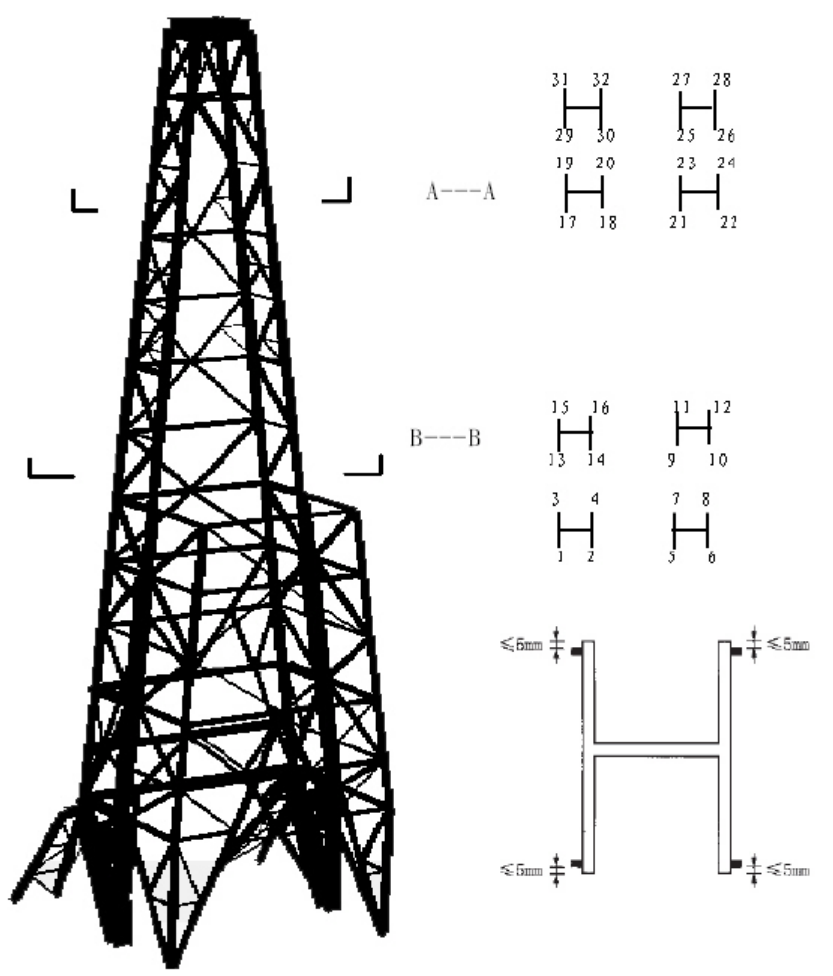

Fig. (3). Arrangement of test points and strain gauges of loading stress test.

\subsection{Constraints}

Derrick is installed on the drill floor, and the derrick floor can be taken as a rigid body because of its big stiffness. The A-bracket inclined leg of mast support is fixed connection with the drill floor, and six degrees of freedom are restricted. The A-bracket backside inclined leg of mast support is connected with the drill floor by 4 pins, and five degrees of freedom are restricted at the pin nodes, the rotational degree 


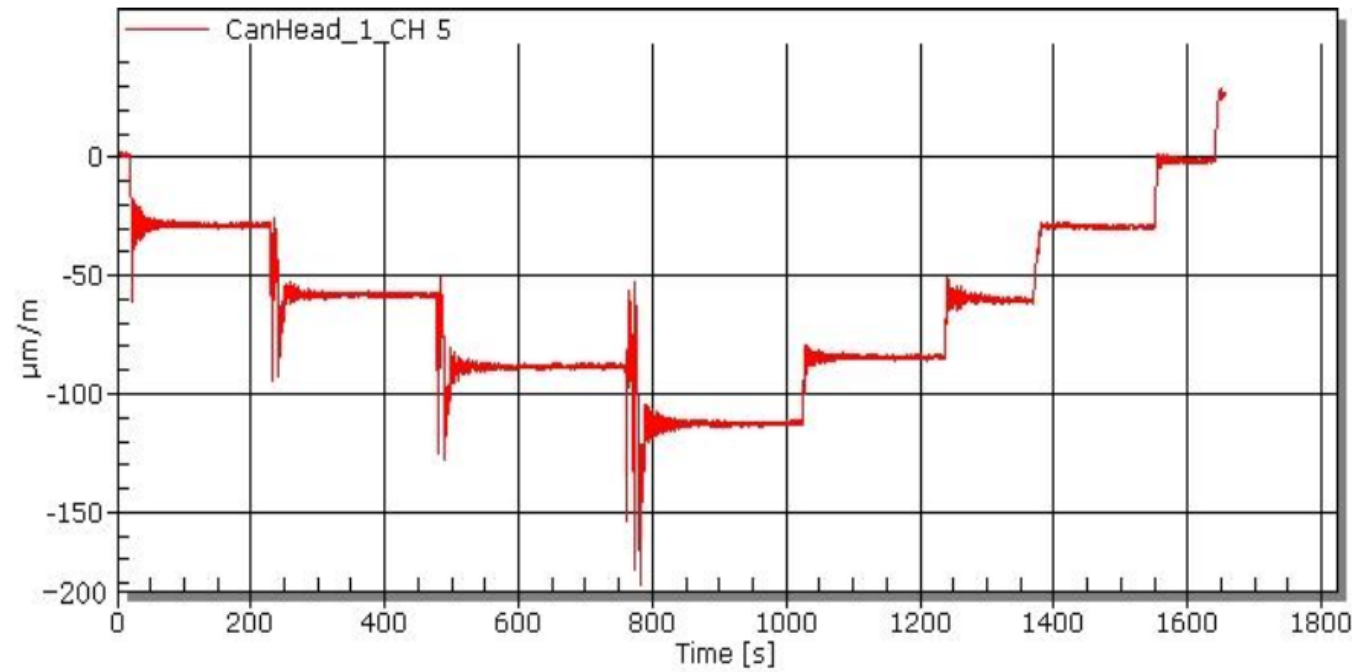

Fig. (4). Strain curves of loading process for the test point No. 9.

Table 2. The actual measured strain values under the load of $1462.3 \mathrm{kN}$.

\begin{tabular}{|c|c|c|c|c|c|c|c|}
\hline Point No. & $\begin{array}{c}\text { Strain Values } \\
(\mu \varepsilon)\end{array}$ & Point No. & $\begin{array}{c}\text { Strain Values } \\
(\mu \varepsilon)\end{array}$ & Point No. & $\begin{array}{c}\text { Strain Values } \\
(\mu \varepsilon)\end{array}$ & Point No. & $\begin{array}{c}\text { Strain Values } \\
(\mu \varepsilon)\end{array}$ \\
\hline 1 & 95.8 & 9 & 191.1 & 17 & 35.2 & 25 & 156.7 \\
\hline 2 & 85.4 & 10 & 181.1 & 18 & 42.1 & 26 & 140.9 \\
\hline 3 & 57.9 & 11 & 143.3 & 19 & 50.1 & 27 & 116.5 \\
\hline 5 & 63.6 & 13 & 139.1 & 21 & 87.2 & 29 & 124.8 \\
\hline 6 & 54.5 & 14 & 133.2 & 22 & 90.2 & 30 & 56.7 \\
\hline 7 & 47 & 15 & 149.9 & 23 & 60 & 31 & 117.3 \\
\hline 8 & 67.1 & 16 & 134.4 & 24 & 78.1 & 32 & 117.4 \\
\hline
\end{tabular}

Table 3. The stress values by extrapolating hook load of $6500 \mathrm{kN}$.

\begin{tabular}{|c|c|c|c|c|c|c|c|}
\hline Point No. & $\begin{array}{l}\text { Stress Value } \\
\text { (MPa) }\end{array}$ & Point No. & $\begin{array}{c}\text { Stress Value } \\
\text { (MPa) }\end{array}$ & Point No. & $\begin{array}{c}\text { Stress Value } \\
\text { (MPa) }\end{array}$ & Point No. & $\begin{array}{l}\text { Stress Value } \\
\quad \text { (MPa) }\end{array}$ \\
\hline 1 & 89.4 & 9 & 178.4 & 17 & 32.2 & 25 & 146.2 \\
\hline 2 & 79.8 & 10 & 169 & 18 & 40.3 & 26 & 131.5 \\
\hline 3 & 54 & 11 & 133.7 & 19 & 56.3 & 27 & 108.7 \\
\hline 5 & 59.4 & 13 & 129.9 & 21 & 81.4 & 29 & 116.5 \\
\hline 6 & 50.8 & 14 & 124.3 & 22 & 84.2 & 30 & 52.9 \\
\hline 7 & 43.8 & 15 & 139.9 & 23 & 56 & 31 & 109.5 \\
\hline 8 & 62.5 & 16 & 125.4 & 24 & 72.9 & 32 & 109.6 \\
\hline
\end{tabular}

of freedom around the pin shaft direction $(Z)$ is not restricted. The vertical legs of mast support is connected with the drill floor by 2 pins, and five degrees of freedom are restricted at the pin nodes, the rotational degree of freedom around the pin shaft direction $(Z)$ is not restricted. Meanwhile, vertical frame legs of auxiliary derrick lower is connected with the drill floor by 2 pins, and five degrees of freedom are restricted at the pin nodes, the rotational degree 
of freedom around the pin shaft direction $(Z)$ is not restricted. The mast support is connected with lower derrick by 2 pins, five degrees of freedom are restricted at the pin nodes, and the rotational degree of freedom around the pin shaft direction $(Z)$ is not restricted. The above description is shown as Fig. (5). In addition, the connection points between lower derrick and auxiliary derrick are 6 , they are all handled as hinge, that is, five degrees of freedom are restricted at the pin nodes and the rotational degree of freedom around the pin shaft direction $(Z)$ is not restricted.

\subsection{Loads}

The loadings mainly include the following types:

Dead Load: Including the weight of crown, traveling block hook, top drive and guide rail, racking platform and derrick. Besides weight of the derrick, other loads are applied on derrick through the crane beam.

Working Load: Including the static hook load and rope work force, the maximum hook load is $4500 \mathrm{kN}$ according to the requirement, and their acting position is as the same with that of dead load.

Setback Load: Including the force acting on derrick because of thribble weight and wind load suffered by pipe, and the setback load is acted on corresponding node of derrick along the horizontal direction by the beam on racking platform.

Wind Load: Including three kinds of wind speed and three kinds of the wind direction. According to API SPEC $4 \mathrm{~F}$ [11], the extreme wind speed of offshore drilling derrick is 48 knots in working condition, 70 knots for unexpected situations, and 93 knots for expected situations. In order to more comprehensive comparison, the direction of wind can be divided into front wind, back wind and lateral wind with reference to the mouth direction of the well. The wind load is applied to all the nodes bearing the wind load.

Earthquake Load: According to the requirements of resistance to 8 magnitude earthquake intensity, the horizontal inertial load of $0.5 \mathrm{~g}$ and the vertical inertial load $0.25 \mathrm{~g}$ are imposed on all nodes.

Top Drive Torque: The guide rail of top drive is connected with the reaction torque beam on the derrick, top drive torque is passed to the derrick by the reaction torque beam, the point of action are the junction points of top drive guide rail and reaction torque beam.

\subsection{Combined Conditions}

According to API SPEC 4F, the main three design loading conditions should be considered for the offshore drilling derrick in service when the erection condition is ignored. They are working conditions, expected conditions and unexpected conditions. From the above load conditions, 13 kinds of working conditions can be combined for FEA. The combinations of working conditions are shown in Table 4.

\subsection{Result Analysis}

FEA are carried out on derrick of OMDR under 13 kinds of working conditions by software ANSYS, and the calculation results are shown as Table $\mathbf{5}$.

Fig. (6) is the composite deformation diagram, and Fig. (7) is the axial stress diagram, which are both derived under the maximum hook load condition.

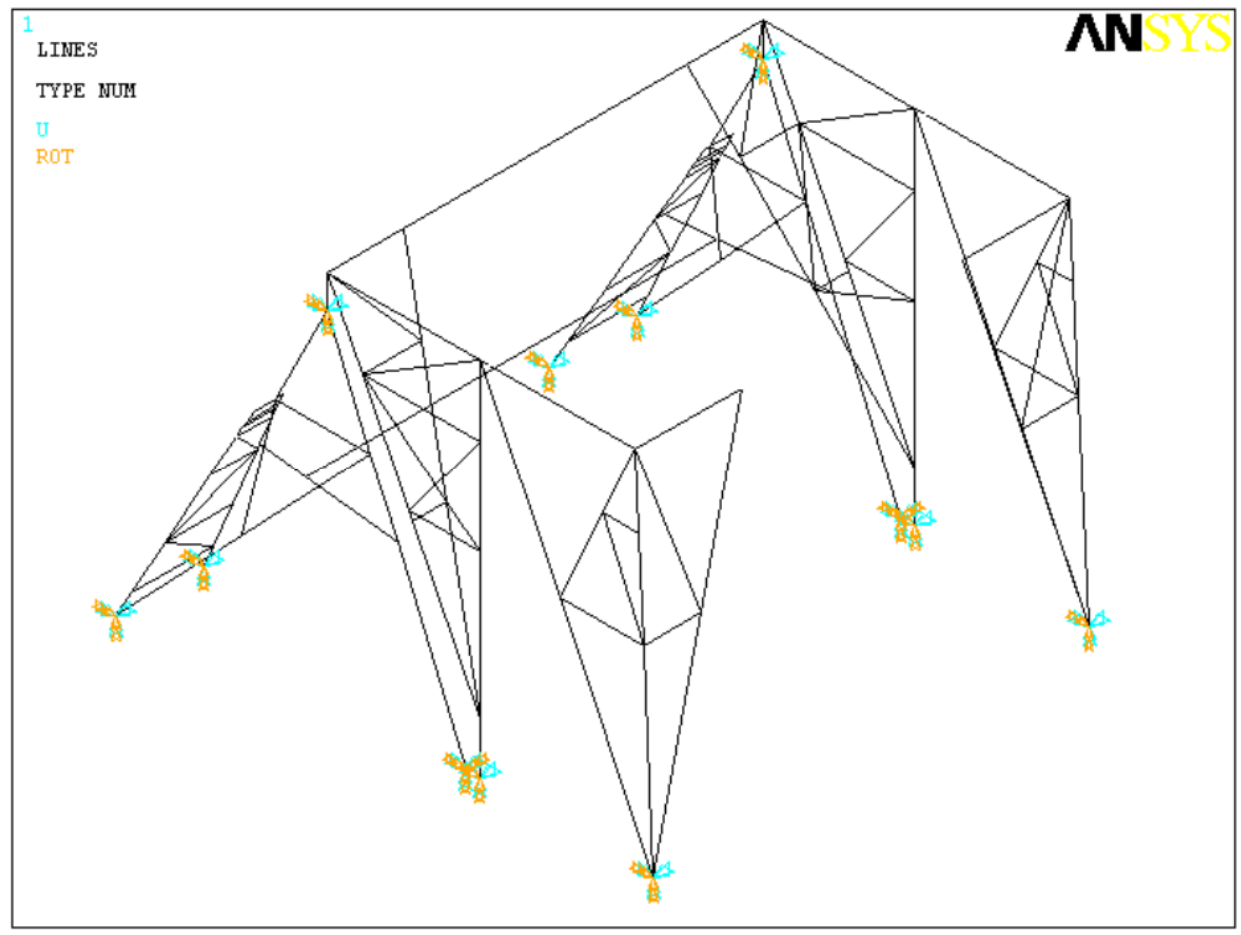

Fig. (5). Constraint sketch for the derrick of OMDR. 
Table 4. Combinations of working conditions.

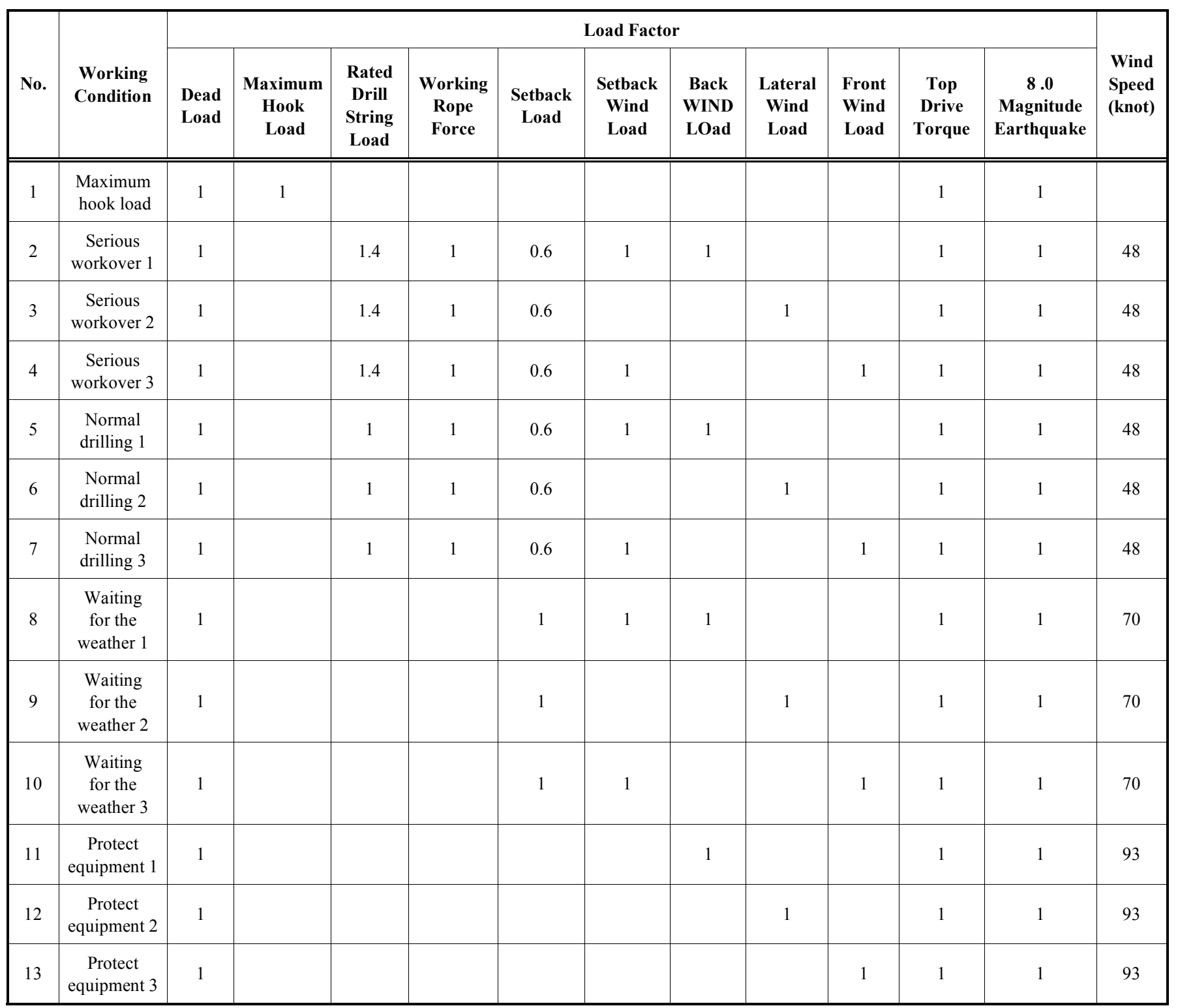

According to the relevant material analysis, the derrick material is equivalent to ASTM A572 Grade 50, the yield stress of which is $345 \mathrm{MPa}$. By API standard for offshore steel structure, the ratio of minimum yield stress and maximum stress value under the maximum hook load should not be less than 1.67. The permissible stress of the derrick is calculated as $[\sigma]=345 / 1.67$, and the result is approximately equal to $206 \mathrm{MPa}$. Some conclusions can be drawn as follows:

(1) The maximum axial compressive stress appears under the maximum hook load condition, and its value is $171 \mathrm{MPa}$, whose position is in the left diagonal on the back of the second section of the upper derrick, and the value is less than the permissible stress. So the derrick axial strength is enough here.

(2) The largest composite deformation occurs under maximum hook load condition, and the value is $60.9 \mathrm{~mm}$, whose position is on the right back derrick leg of the first section of the upper derrick, even if using the shortest rod of the first section to calculate, the length is about $2000 \mathrm{~mm}$, and the maximum deformation is less than $3 \%$, which is very small. So the stiffness of this derrick is sufficient.

(3) For the four derrick legs which are the main carrier, all the maximum axial stress is less than $125 \mathrm{MPa}$, which is far less than the permissible stress of derrick. So the axial carrying strength is enough.

\section{LOAD-CARRYING CAPACITY ASSESSMENT}

\subsection{Assessment Method}

In order to overcome the limitation of load-carrying capacity assessment method by linear extrapolation based on limited measuring point data in field test, the method combining the field test with computer simulation technology is adopted in this study. In addition to use the conventional 
Table 5. FEA calculation results of different working conditions.

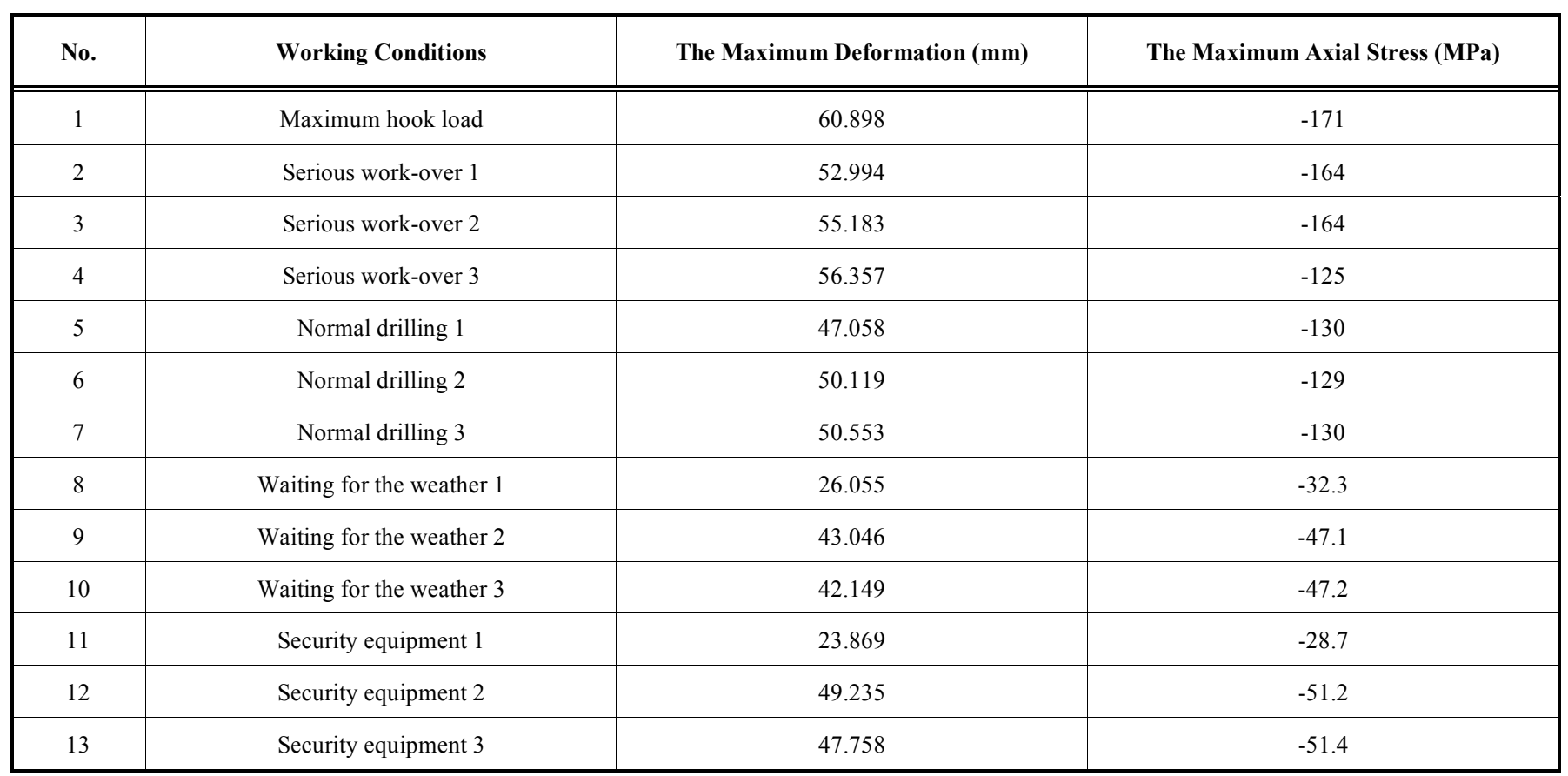

\begin{tabular}{|ll|}
\hline NODAL SOLUTION & NN \\
STEP $=1$ & \\
SUB $=1$ \\
TIME $=1 \quad$ (AVG) \\
USUM \\
RSYS =0 \\
DMX $=.060898$ \\
SMX $=.060898$ & .006766 \\
& .013533 \\
& .020299 \\
& .027066 \\
\end{tabular}

Fig. (6). Composite deformation diagram under $4500 \mathbf{k N}$ hook load.

geometric measurement, ultrasonic thickness measurement, nondestructive test (NDT) to locate the derrick external damage, Stress concentration detection (SCD) can predict the intrinsic defects and damage of the rods in advance and provide more accurate and complete information for establishment of the finite element model and actual assessment model. Assessment combining with SCD is also characteristic of this study. FEA is carried out for the derrick, which can make actual stress, deformation and stress distribution more comprehensive, especially, the dangerous section of derrick got by FEA can be the test point location for loading stress test, and it provide the basis for related test assess- ment. This study on the derrick carrying capacity assessment of OMDR will be conducted from the following aspects:

(1) Analyzing derrick carrying capacity combined with FEA. Derrick is 3D steel structure, the rods of which are mainly bore axial tension and compression and bending force of two directions. Referencing the component of unsymmetric and other members subject to flexure and axial force in Specification for Structural Steel Buildings [12], Eq. (1) should be fulfilled, i.e. under the above combined load, if the strength coefficient of derrick rod is smaller than 1 , which means that the carrying capacity is enough. 


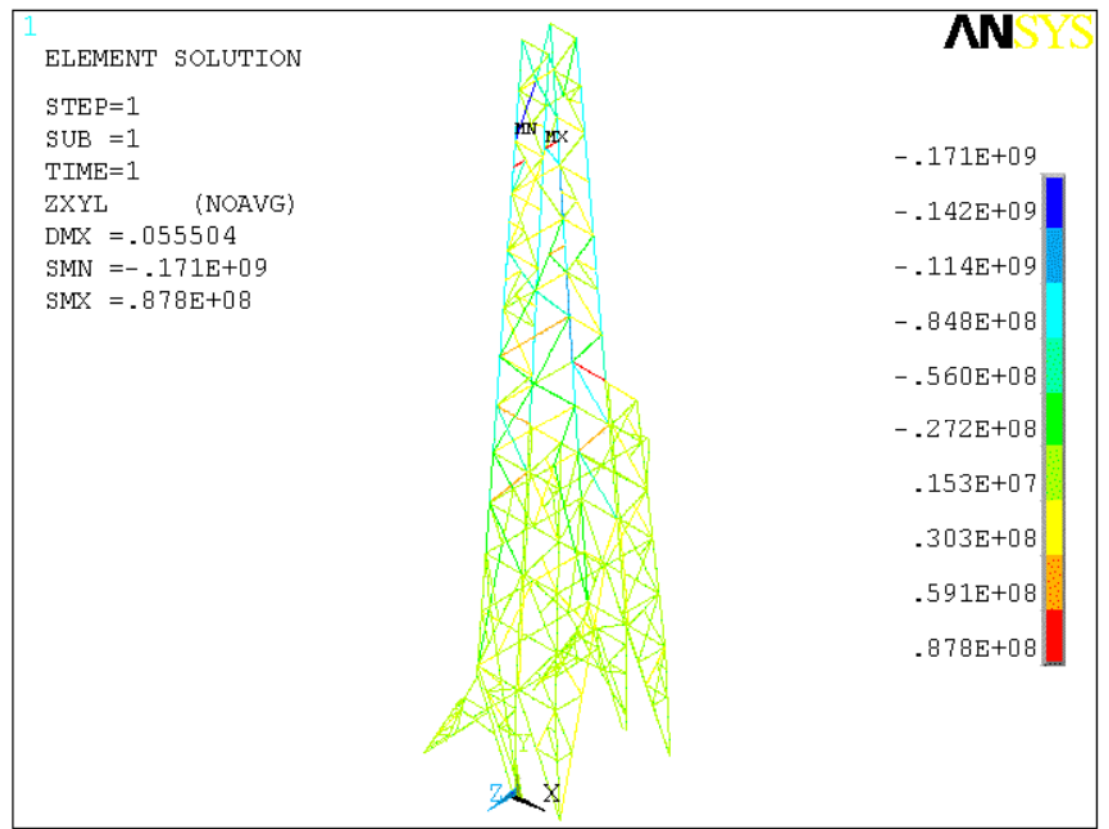

Fig. (7). Axial stress diagram under 4500 kN hook load.

$$
\left|\frac{f_{a}}{F_{a}}+\frac{f_{b w}}{F_{b w}}+\frac{f_{b z}}{F_{b z}}\right| \leq 1.0
$$

where

$f_{a}$ is acquired axial stress, $\mathrm{MPa}$;

$F_{a}$ is allowable axial stress, MPa;

$f_{b w}, f_{b z}$ are acquired bending stress, MPa;

$F_{b w}, F_{b z}$ are allowable bending stress, MPa;

$w$ is subscript relating symbol to major principal axis bending;

$z$ is subscript relating symbol to minor principal axis bending;

For this purpose, we derive axial stress of derrick and bending stress of two curved crankshafts by FEA, respectively. Substituting the above values into Eq. (1), we can check the load-carrying capacity check. It should be pointed out that here the internal defects of stress concentration are also taken into account for model of FEA.

(2) Analyze derrick's load-carrying capacity by using the test data of loading stress. The appropriate test points are selected by the location of maximum axial stress obtained by FEA of derrick leg. Strains of the measuring points are recorded by strain gauge and converted to axial stress and bending stress of the two axes. According to the Specification for Grading and Evaluating the Loading Capacity on Derricks and Substructure of the Drilling Rig and Working Rig [10], load-carrying capacity assessment and rating of derrick are carried out.

(3) Comparing the above two kinds of assessment results, the actual load-carrying capacity of offshore module drilling rig derrick is derived, and the smaller value of actual load-carrying capacity can be used as the final assessment result.

\subsection{Derrick Carrying Capacity Assessment Based on FEA}

Referring to the above assessment method and Eq. (1), make:

$$
U C=\left|\frac{f_{a}}{F_{a}}+\frac{f_{b x}}{F_{b x}}+\frac{f_{b y}}{F_{b y}}\right|
$$

In order to avoid possible negative value of $\mathrm{UC}$, absolute value was used in Eq. (2). Writing the command flow program of post-processing, UC figure can be shown. When the value of UC less than 1 , it means that carrying capacity meets the requirement. Derrick leg is the main carrying component, whose carrying capacity represents the whole carrying capacity of the derrick. Through FEA, the value of $\mathrm{UC}$ of derrick leg is the biggest under the maximum hook load among 13 kinds of working conditions, and the value is 1.099 , which is greater than 1 , so it means that carrying capacity does not meet the requirement. The result is shown in Fig. (8).

There is no operational instance about how to consider the influence of stress concentration in the FEA of derrick. We know that the cross section mutations along the axial for steel members can lead to stress concentration, so equivalent section reduction is used to reflect the derrick stress concentration of rod, and different degree of section reduction represents different stress concentration degree of this derrick. Due to that the whole stress concentration degree of this derrick is not serious, and the number of bars with stress concentration is not much, according to the experience of the previous analysis, the method of equivalent section reduction can be used. The sections of 11 rods with more serious stress concentration are reduced in a new FEA.

The value of UC of derrick is shown in Fig. (9). Contrasting Fig. (9) with Fig. (8), the value of UC in derrick leg considering the stress concentration is 1.108 , which is slightly 


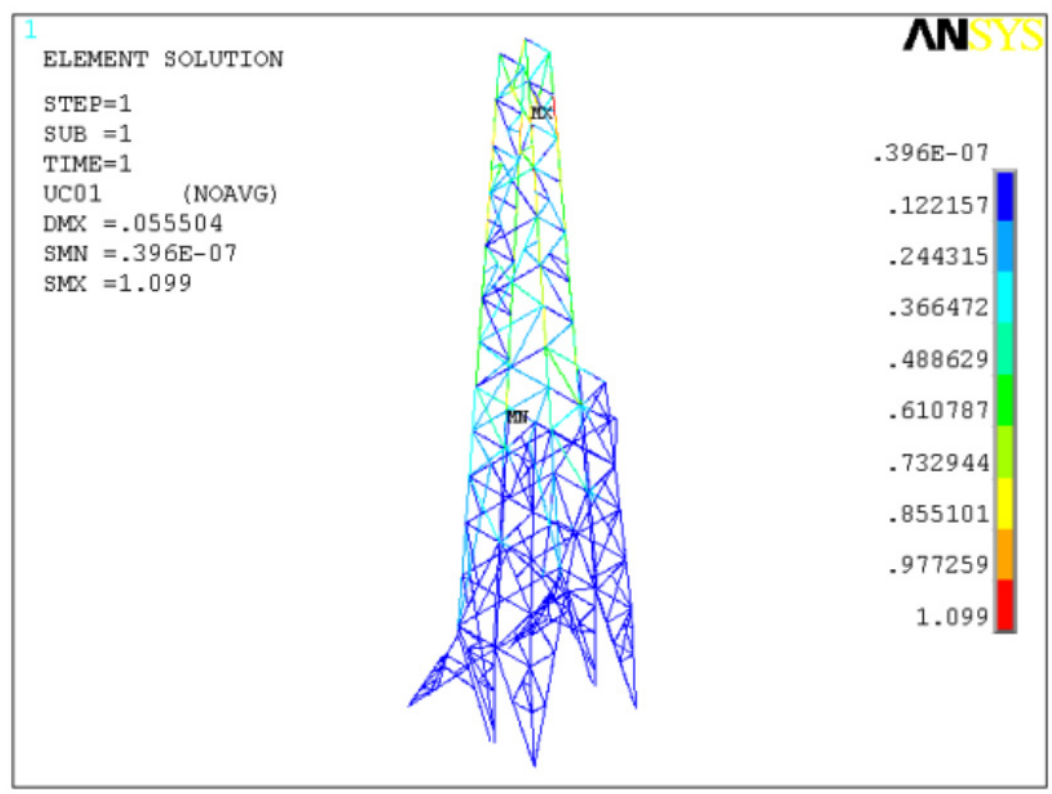

Fig. (8). Derrick leg UC diagram under $4500 \mathrm{kN}$ hook load.

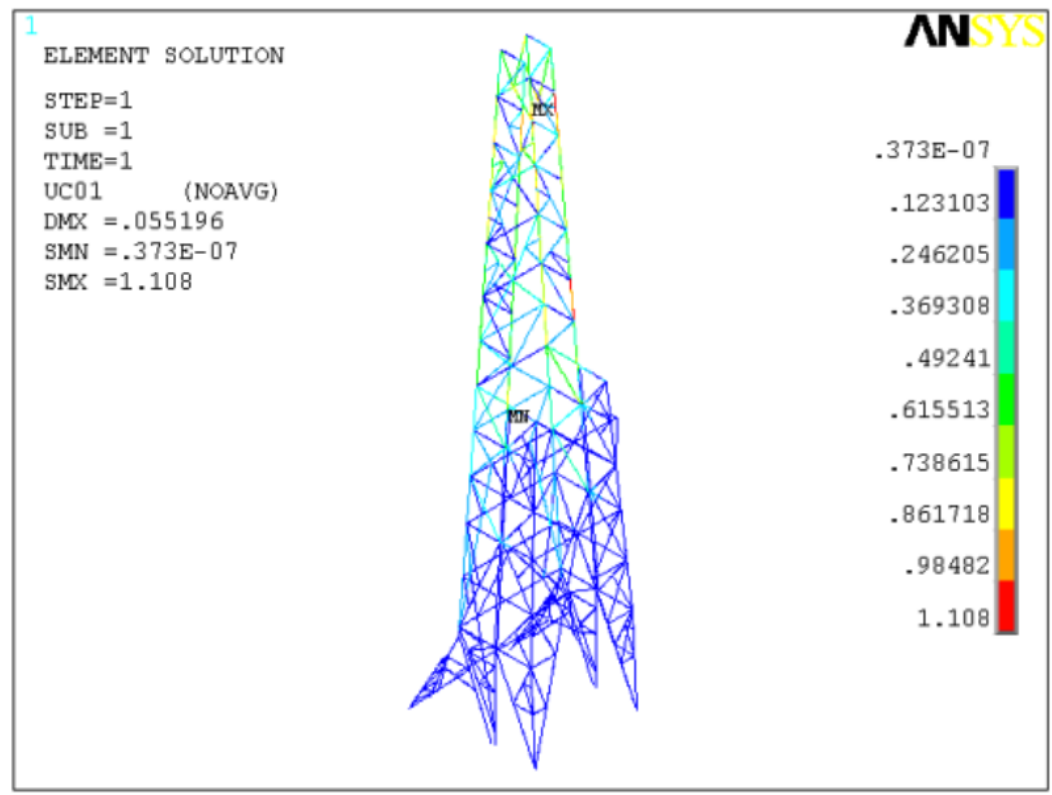

Fig. (9). Derrick leg UC diagram considering stress concentration.

larger than that of not considering the stress concentration, and almost it has no effect. The reason for appearing this phenomenon is that the number of rods with defects of stress concentration is not much, and it has occurred in only two rods on legs, and stress concentration degree is not serious. So the influence of stress concentration for this derrick cannot be considered.

In order to assess the derrick better, we assume that the value of $\mathrm{UC}$ is 1 . Through repeated trials, the actual carrying capacity of this derrick is $4039 \mathrm{kN}$.

\subsection{Derrick Carrying Capacity Assessment Based on Loading Stress Test}

From the data in Table $\mathbf{3}$, according to the method of measurement and evaluation for the loading capacity on der- ricks and substructure of the drilling rig and working rig [10], the derrick carrying capacity can be assessed.

The actual measurements of section size for A-A and B$\mathrm{B}$ are as follows: Length of wing is $300 \mathrm{~mm}$, thickness of wing is $10 \mathrm{~mm}$, length of web is $300 \mathrm{~mm}$, thickness of web is $15 \mathrm{~mm}$, unsupported length 1 is $3700.0 \mathrm{~mm}$, radius of gyration $r_{x}$ is $130.5 \mathrm{~mm}, r_{y}$ is $75.9 \mathrm{~mm}$, the elastic modulus $E$ is $206 \mathrm{GPa}$, yield limit $f$ is $315 \mathrm{MPa}$. Test strength coefficients are shown in Table $\mathbf{6}$.

From the above calculation results of intensity coefficient, we find that the maximum intensity coefficient of derrick is 1.52 , which is significantly larger than 1.00 , so the derrick neither meet the load-carrying capacity of the original derrick with $6500 \mathrm{kN}$, nor meet the need for loadcarrying capacity of $4500 \mathrm{kN}$. 
Table 6. The strength coefficient for tested derrick.

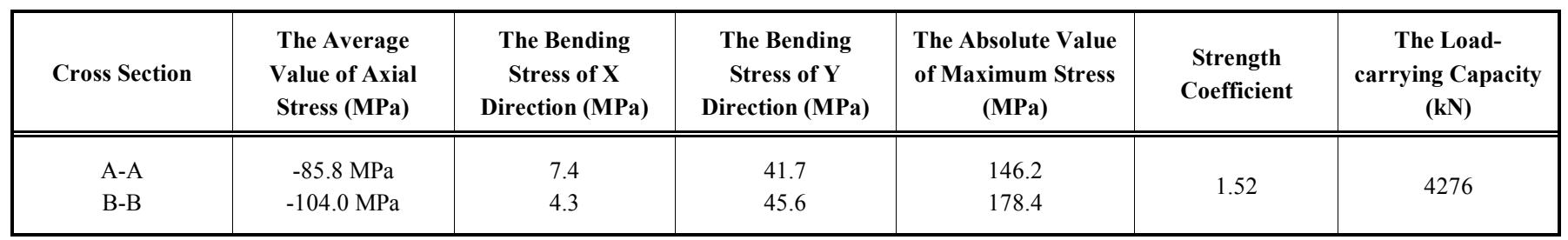

\subsection{Contrast of Stress Test and FEA}

Through the comparative analysis, the position of strain gauge for actual stress test is close to the position of maximum stress derived by FEA, the measured axial stress value and the results of FEA are basically the same. The maximum value occurs on the right back derrick leg of the 7 th section of the derrick. From Table 6, when applying the original derrick maximum hook load 650 tons, the linear extrapolation value of maximum stress measured value of derrick leg is $178.4 \mathrm{MPa}$, and the result of FEA is $186 \mathrm{MPa}$, the error between them is $4.1 \%$, the difference is very small. For the derrick actual carrying capacity, the concluded value of stress test analysis is $4276 \mathrm{kN}$, and the result of FEA is $4039 \mathrm{kN}$, the error between them is $5.5 \%$, the difference is also small. The errors of two cases are both less than $10 \%$ which is the engineering error range. From the above results, we have confirmed that the FEA model is correct and the loading stress test result is dependable. Considering about the security, the actual carrying capacity limit can be used the smaller value of the two analysis results, and the value is $4039 \mathrm{kN}$.

\section{STRUCTURE REINFORCEMENT SIMULATION}

According to the former load-carrying capacity assessment result of derrick, the derrick cannot meet the requirements of the hoisting capacity of $4500 \mathrm{kN}$. So the structural reformation is needed. Because derrick carrying capacity is insufficient on the back legs of the upper derrick, which are the main carrying components for derrick, two kinds of reinforcement schemes are put forward as followings: The first method is welding reinforcement plates to the two H-beam on the back legs of the upper derrick (back legs reinforcement scheme) which is shown in Fig. (10a); the second method is welding reinforcement plates to the four H-beam on the front and back legs of the upper derrick (four legs reinforcement scheme) which is shown in Fig. (10b). The structure of reinforcement is welding $10 \mathrm{~mm}$ plates on the front and back of H-beam. The FEA is carried out respectively on the derricks with two method reinforcement schemes, and the results are shown in Figs. (11 and 12).

From Fig. (11), when back legs reinforcement scheme is adopted, the weakness points (where the value of UC is maximum) of load-carrying capacity lie on the front legs comparing with the previous results, the max value of UC reflecting load-carrying capacity of derrick legs is smaller than that of the value which is derived without reinforcement situation, but the value is still larger than 1 , so the derrick carrying capacity is promoted, but it still cannot meet the requirements of hoisting capacity of $4500 \mathrm{kN}$. Fig. (12) shows the value of UC of derrick leg in four legs reinforcement scheme, the weakness points of carrying capacity lie on the back legs. The max value of UC is less than 1 , it means that the derrick carrying capacity is promoted obviously by using four legs reinforcement scheme, and the derrick can meet the requirements of hoisting capacity of $4500 \mathrm{kN}$. Therefore the four legs reinforcement scheme is adopted to restore the derrick carrying capacity.

\section{CONCLUSION}

Based on the load-carrying capacity assessment and structure reinforcement for derrick of OMDR, the results can be drawn as follows:
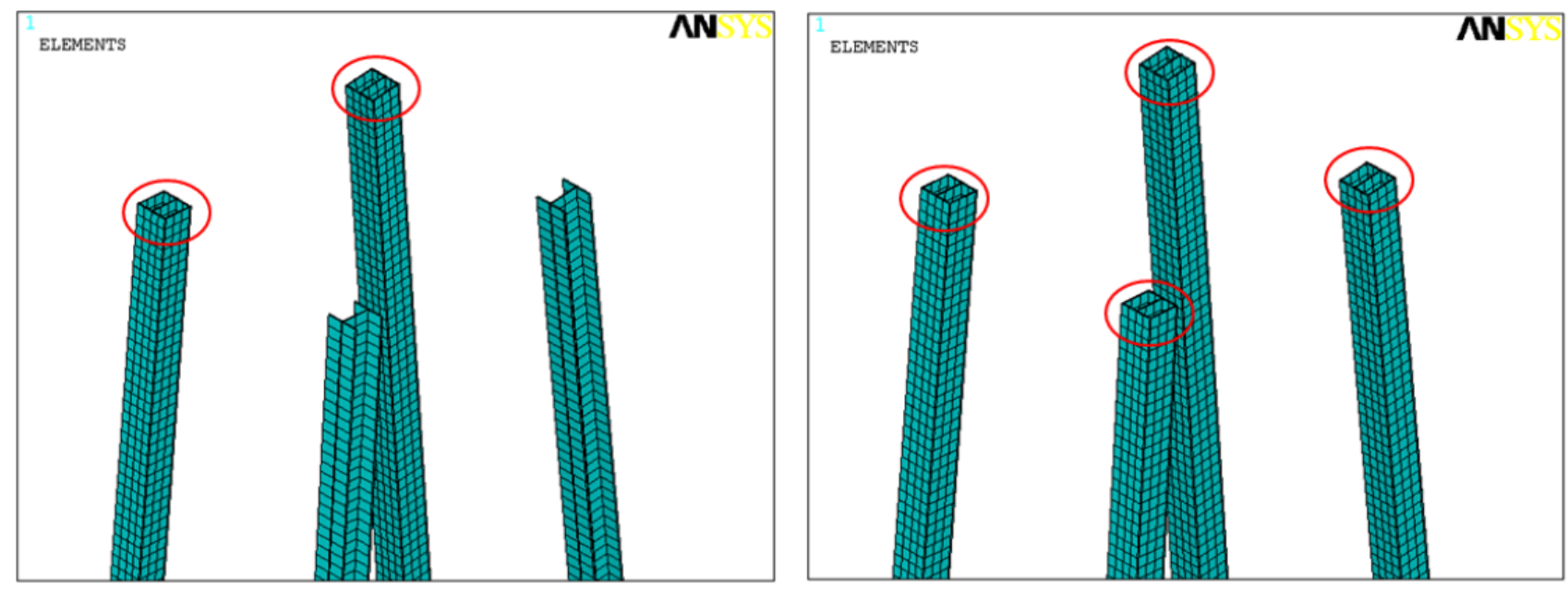

Fig. (10). (a) Back legs reinforcement scheme. (b) Four legs reinforcement scheme. 


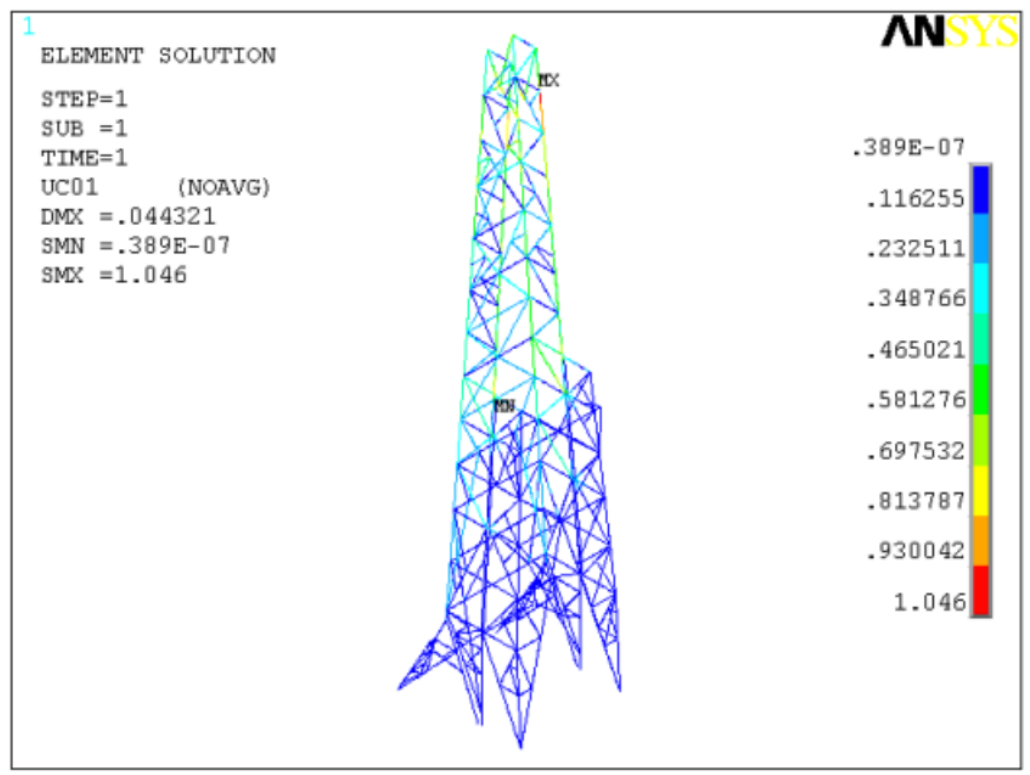

Fig. (11). UC diagram of back legs reinforcement scheme.

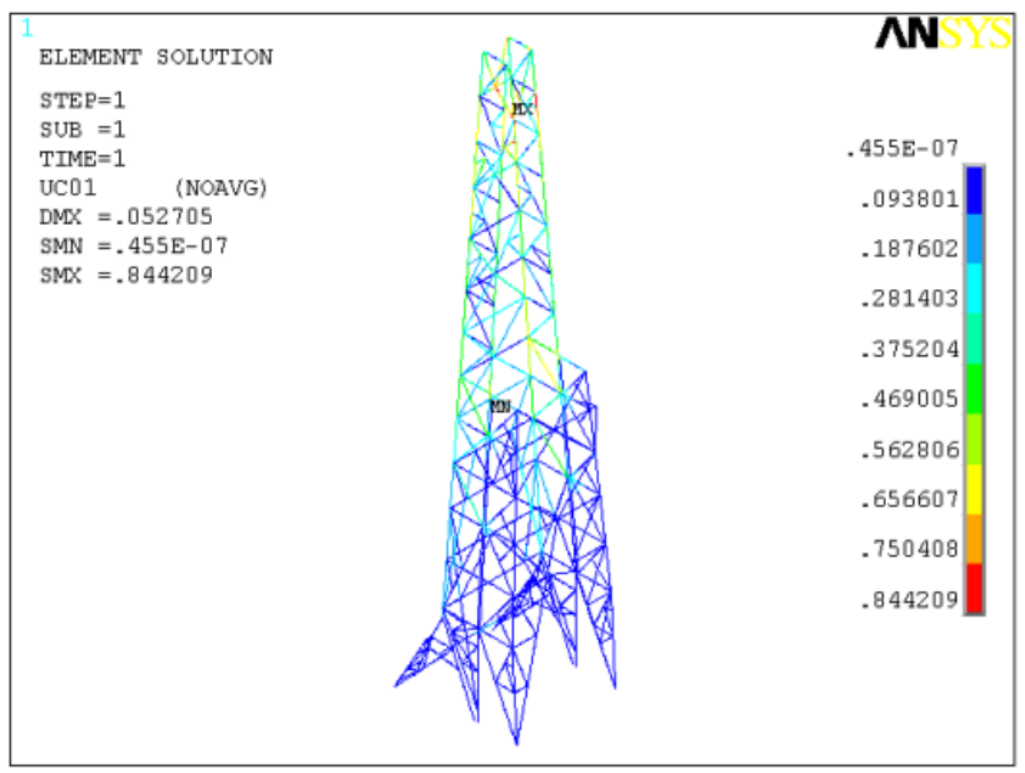

Fig. (12). UC diagram of four legs reinforcement scheme.

(1) By loading stress test, NDT and FEA on the derrick of OMDR, the derrick carrying capacity is insufficient when the required hoisting load is $4500 \mathrm{kN}$. The actual derrick carrying capacity is $4039 \mathrm{kN}$, if the derrick is still used for drilling operation, the maximum hook load of hoisting system should be limited strictly within the value.

(2) SCD on the main rods of derrick are carried out by the metal magnetic memory detector, according to the results there are 11 rods which are of a large stress concentration, and stress concentration degree are serious for some rods. But the whole stress concentration degree of derrick is not serious. By FEA analysis on derrick including some stress concentration defects rods, the derrick carrying capacity is close to that of value which is obtained without considering the stress concentration defects. So the stress concentration defects can be unconsidered.
(3) Thought the repeated comparison and analysis calculation by FEA software, in order to make the derrick hoisting capacity reach $4500 \mathrm{kN}$, the method that welding reinforcement plates to the four H-beam on the front and back legs of the derrick can be used, and the thickness of weld plates is $10 \mathrm{~mm}$, but the further SCD should be carried out after the completion of the reinforcement.

\section{CONFLICT OF INTEREST}

The authors confirm that this article content has no conflicts of interest.

\section{ACKNOWLEDGEMENTS}

This study was jointly supported by Natural Science Foundation of Hubei Province of China (No. 2013CFC127), 
PetroChina Innovation Foundation (No. 2012D-5006-0307) and National Natural Science Foundation of China (No. U1262108).

\section{REFERENCES}

[1] B. Avignon, and A. Simondin, "Deep water drilling performance", In: SPE Annual Technical Conference and Exhibition, September 29-October 2, 2002, San Antonio, Texas, USA, 2002, pp. 227-239.

[2] L. Munch-Soegaard, and A. Nergaard, "Offshore drilling experience with dual derrick operations", In: SPE/IADC Drilling Conference, February 27-March 1, 2001, Amsterdam, Netherlands, 2001, pp. 154-159.

[3] J. Geyelin, A. Clergier, R. Bouget and X. Manchon, "Completion of Aconcagua Field With a Dual Derrick Drilling Unit", In: SPE Annual Technical Conference and Exhibition, October 5-October 8, 2003, Denver, Colorado, USA, 2003, pp. 2533-2539.

[4] Y.L. Guo, and Y. Fukumoto, "Theoretical study of ultimate load of locally buckled stub columns loaded eccentrically". Journal of Constructional Steel Research, vol. 38, no. 3, pp. 239-255, 1996.

[5] G.M. Barsan, and C.G. Chiorean, "Computer program for large deflection elasto-plastic analysis of semi-rigid steel frameworks", Computers and Structures, vol. 72, no. 6, pp. 699-711, 1999.

[6] Q.H. Han, and X.L. Liu, "Ultimate bearing capacity of the welded hollow spherical joints in spatial reticulated structures", Engineering Structures, vol. 26, no. 1, pp. 73-82, 2004.
[7] D.Y. Han, Z.F. Li, and G.Q. Zhou, "Ultimate bearing capacity analysis of derrick steel structures based on partial model updating theory", Engineering Mechanics (in Chinese), vol. 24, no. 10, pp. $175-179,2007$.

[8] .M. Liu, G.Q. Zhou, and D.Y. Han, "Study on simulation for ultimate bearing capacity of oil-derrick with damage", Journal of System Simulation (in Chinese), vol. 21, no. 6, pp. 1781-1784, 1788, 2009.

[9] A.A. Doubov, "Diagnostics of metal items and equipment by means of metal magnetic memory", In: Proceedings of ChSNDT $7^{\text {th }}$ Conference on NDT and International Research Symposium, October 27-October 30, 1999, Shantou, Guangdong, China, 1999, pp. 181-187.

[10] Quality supervision \& inspection center of well control equipment for petroleum industry, SY 6326-2012. The specification for grading and evaluating the loading capacity on derricks and substructure of the drilling rig and working rig (in Chinese). Beijing: China Petroleum Industry Press, 2012.

[11] American Petroleum Institute, API SPEC 4F Specification for Drilling and Well Servicing Structures. Washington, D.C.: API Publishing Services, 2008.

[12] American Institute of Steel Construction, ANSI/AISC 360-05 Specification for Structural Steel Buildings. Chicago: AISC Board of Directors, 2005.

Received: March 06, 2014

(C) Guan et al.; Licensee Bentham Open.

This is an open access article licensed under the terms of the Creative Commons Attribution Non-Commercial License (http://creativecommons.org/licenses/by-nc/3.0/) which permits unrestricted, non-commercial use, distribution and reproduction in any medium, provided the work is properly cited. 